\title{
e-Representação como comunicação política: Internet e democracia representativa'
}

\section{e-Representation as political communication: Internet and representative democracy}

\section{Arthur Ituassu}

Professor do Programa de Pós-Graduação em Comunicação Social da Pontifícia Universidade Católica do Rio de Janeiro, pesquisador no Centro de Estudos Avançados em Democracia Digital, vice-presidente da Associação Brasileira de Pesquisadores em Comunicação e Política (2015-2017).

<ituassu@puc-rio.br>

\section{RESUMO}

Este é um trabalho de cunho teórico que analisa potenciais impactos da Web para a representação política em regimes democráticos. Seu objetivo, assim, é discutir, no plano teórico, a relação entre comunicação política digital e representação democrática. Para tanto, analisa-se o lugar da representação política nas teorias política e democrática, com especial foco na literatura mais recente sobre o tema, a relação entre representação e comunicação social e as possíveis contribuições da Web para a prática representativa em regimes democráticos. Ao fim, sugere-se que, ao se pensar a relação entre internet e representação, a preocupação deve ser menos a de estabelecer vínculos diretos ou interatividade entre representantes e representados e mais a de promover a participação e a deliberação na representação, no ambiente on-line.

Palavras-chave: Internet e democracia. Internet e representação. e-Representação.

\begin{abstract}
This is a theoretical research that analyzes potential impacts of the Web for political representation in democratic regimes. Hence, the aim of this paper is to discuss a theory about the relations of digital political communication and democratic representation. For this, it will debate the place of political representation in democratic and political theories, with special attention to the most recent literature about the matter, the intersections of political representation and social communication, and the potentialities of the Web for representative practices in democratic regimes. In the end, it suggests that digital initiatives for democratic representation should worry less about establishing interactivity or a more direct communication between representatives and represented, and more about strengthening participation and deliberation in representation on the Internet.
\end{abstract}

Keywords: Internet and Democracy. Internet and Representation. e-Representation.

\section{INTRODUÇÃO}

A chegada da internet, não há dúvidas, causou um grande impacto no campo da Comunicação e Política. Com o advento tecnológico, um sem número de estudos sobre internet e democracia passaram a ser desenvolvidos nos mais variados ramos da comunicação política digital, seja no campo do

1 Trabalho realizado com o apoio do Conselho Nacional de Desenvolvimento Científico e Tecnológico (CNPq/Brasil). 
participacionismo (Gomes; Maia, 2008; Maia; Gomes; Marques, 2011; Coleman; Blumler, 2010), do deliberacionismo (Miola, 2011; Maia, 2012; Dahlgren, 2001), ou do liberalismo (Welsch, 2012; Naurin; Fellow; Shuman, 2007). Isso sem falar sobre as análises produzidas sobre ativismo, reconhecimento, eleições, campanhas, opinião pública, jornalismo político, etc. (Aggio, 2011; Marques; Sampaio; Aggio, 2013; Garcêz, 2011; Chadwick; Howard, 2009).

Nesse contexto, este trabalho se posiciona no espaço reservado para o debate sobre as potencialidades da internet para a representação democrática, fazendo parte de uma tradição originada de questionamentos sobre de que forma os recursos da Web poderiam aprimorar a democracia, tornando as autoridades mais responsivas durante a prática representativa, ou seja, de que maneira esses mesmos recursos poderiam reforçar os processos de accountability não-eleitoral (Maia, 2008; Richard, 1999; Hale; Mussom; Weare, 1999; Coleman; Blumler, 2010; Karlsson, 2013). Em meio a essa discussão, o objetivo aqui é debater uma teoria sobre comunicação política digital e representação democrática. Para tanto, analisa-se o lugar da representação nas teorias política e democrática, a relação entre representação e comunicação e as possíveis contribuições da Web para a prática representativa. Ao fim, sugere-se que, ao se pensar a relação entre internet e representação, a preocupação deve ser menos a de estabelecer vínculos diretos ou interatividade entre representantes e representados e mais a de promover a participação e a deliberação na representação no ambiente online, que possam reforçar as demandas por responsividade e multiplicar as oportunidades de participação e de deliberação na construção social da representação.

\section{DEMOCRACIA E REPRESENTAÇÃO}

Uma ampla literatura ressalta hoje um conjunto de fenômenos históricos e sociais recentes que teriam modificado as condições nas quais a representação política se desenvolve nas democracias contemporâneas (Mansbridge, 2003; 2004; Näsström, 2011; Saward, 2010; Castiglione; Warren, 2006; Shapiro e outros., 2009; Vieira; Runciman, 2008; Urbinati, 2008; Rehfeld, 2009). Castiglione e Warren (2006), por exemplo, apontam para uma crise no pensamento comum (standard) da representação política, que se limitaria a conceber a prática representativa às formas eleitorais de base territorial. Os autores ressaltam o surgimento de arenas decisórias transnacionais, onde proliferam atores e temas de natureza não-territorial e que escapariam do alcance da representação com 
base no voto e circunscrita ao Estado-nação. Além disso, boa parte dessas arenas estaria hoje sob o controle de especialistas, cujas trajetórias percorrem caminhos distantes das tradicionais instituições da democracia representativa.

Ao mesmo tempo, o caráter igualitário da democracia representativa moderna vem sendo relativizado por demandas de reconhecimento, equalização ou compensação de grupos estabelecidos por características, identidade ou condições, demandas estas que estariam produzindo um discurso de representação com base em lógicas diferentes daquelas ligadas ao igualitarismo e universalismo do modelo eleitoral e territorial (Young, 2006; 2011). Nesse contexto, ressalta-se também a difusão de novas estruturas e oportunidades para a representação e a influência política, que se constituíram da crescente diversificação das formas público-discursivas e de associação (Castiglione; Warren, 2006, p. 2-3).

Não à toa, alguns autores alertam para a diluição das certezas sobre "quem 'fala', por quem e com que autoridade" (Näsström, 2011, p. 501-502). Nesse terreno, Lavalle e Castello (2006), por exemplo, a partir de um estudo feito nas cidades do México e de São Paulo, concluíram ser necessário cultivar um certo "ceticismo", em termos de representação e democracia, frente ao crescente avanço de organizações civis como agentes de intermediação política.

Mesmo reconhecendo a relevância dessa discussão, importa menos, para este trabalho, debater a legitimidade das representações de tipo nãoeleitoral e não-territorial e mais perceber o quanto a teoria da representação se tornou mais densa nos últimos anos, ora pensada a partir de uma "crise de representação" ou "crise da democracia representativa" (Miguel, 2003; Lavalle; Araujo, 2006; Lavalle; Houtzager; Castello, 2006), ora concebida através da necessidade de se reconfigurar os processos representativos a novas condições (Mansbridge, 2003; 2004; Castiglione; Warren, 2006; Saward, 2010). Originadas da comunicação política, da sociedade civil, das relações internacionais ou da própria teoria democrática (Lavalle; Araujo, 2006, p. 10), novas perspectivas e teorias foram desenvolvidas com o objetivo de reafirmar a própria posição da representação na teoria da democracia (Näsström, 2011; Saward, 2010; Vieira; Runciman, 2008).

Nesse contexto, vale chamar a atenção, é retomada a qualidade relacional da representação (Castiglione; Warren, 2006; Urbinati, 2008; Petit, 2009; Saward, 2010), normalmente resgatando tal aspecto do trabalho canônico de Hannah Pitkin (1967). Como sugeriu Pitkin, a representação é uma relação social, onde estão, ao mesmo tempo, a autonomia relativa dos representantes e os direitos de soberania do representado. Para a autora, o cerne da democracia 
representativa estaria na noção de que as instituições políticas, por meio dos seus representantes, contemplarão os desejos dos cidadãos ou serão, ao menos, responsivos a eles (Pitkin, 1967).

Dessa forma, como lembram Castiglione e Waren (2006), Pitkin constitui uma ontologia da representação como uma relação social constituída de significados (políticos) compartilhados. Isso, ao entender deste trabalho, é menos uma questão sobre a legitimidade das representações não-eleitorais e mais um posicionamento da representação na teoria política e democrática em um patamar tão abrangente quanto, ou mesmo mais abrangente que, a própria democracia. Afinal, se a representação política é tida como uma relação social de significados políticos compartilhados, a representação democrática se apresenta como uma especificidade. Trata-se, assim, de se pensar, a lá Dewey, a democracia na representação, como ilustrado na Figura 1 a seguir.

Figura 1: Democracia na representação

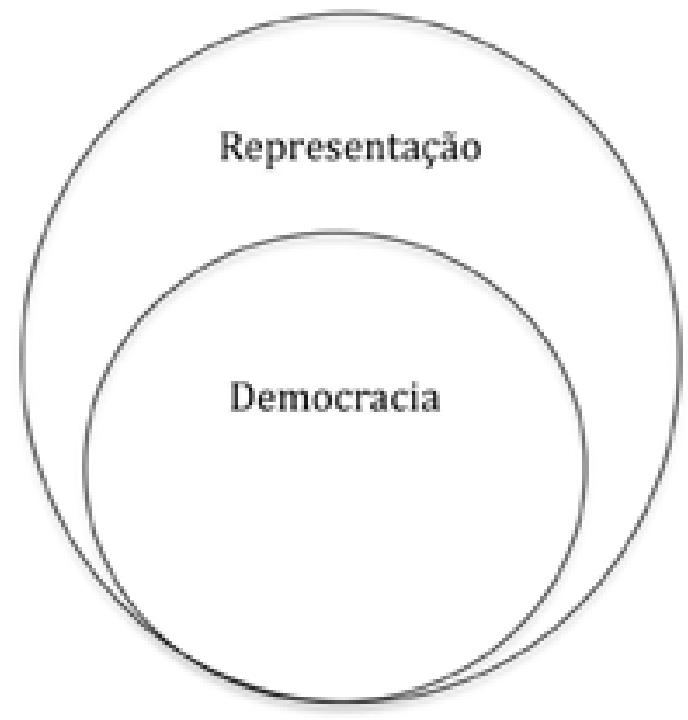

A partir de tal (re)posicionamento, uma possibilidade se apresenta: a de pensar as perspectivas normativas da teoria democrática na representação, isto é, liberalismo na representação, participacionismo na representação e deliberacionismo na representação (Petit, 2009; Castiglione; Warren, 2006; Mendonça, 2008, p. 130; Plotke, 1997; Gomes, 2011). Sobre o primeiro ponto, vale perceber que o liberalismo, dentre as três grandes correntes da teoria da democracia, não apresenta grandes questões à representação. Pelo contrário, para um liberal, o regime representativo garante a divisão de poderes e enfraquece a possibilidade de tiranias, de minorias ou maiorias (Held, 2006, 
p. 56-95). Dessa forma, o próprio termo "liberalismo na representação" seria desnecessário, bastando "liberalismo", mas foi feita a opção de se manter a qualificação “liberalismo na representação" de modo a posicionar a perspectiva liberal ao lado da participacionista e deliberativa como visões normativas da teoria democrática, ou seja, em um patamar inferior ao da democracia e, por conseguinte, da própria representação.

Os casos do deliberacionismo e do participacionismo são, entretanto, diferentes, dado que as duas correntes podem ser apresentadas como, ao menos em última instância, formas substitutivas da representação. Assim, enquanto iniciativas mais participativas, propriamente ditas, almejariam um input efetivo no processo decisório, a participação na representação manteria a autonomia relativa do representante, mas atuaria discursivamente de modo a reforçar as demandas por responsividade. De modo semelhante, enquanto o deliberacionismo pensado per se traria à tona a chamada "segunda agenda" (Dahlgren, 2001), isto é, aquela relativa ao impacto efetivo da deliberação na decisão política, a deliberação na representação se distinguiria da proposta deliberativa propriamente dita ao não colocar ênfase na noção de "esfera intermediária" entre o debate público e a decisão política, garantindo a autonomia relativa do representante, mas no seu papel potencializador de contextos discursivos que possam reforçar as demandas por responsividade por parte dos representantes. Dessa forma, localiza-se a representação e as teorias normativas da democracia como na Figura 2 a seguir.

FIGURA 2: Liberalismo, participacionismo e deliberacionismo

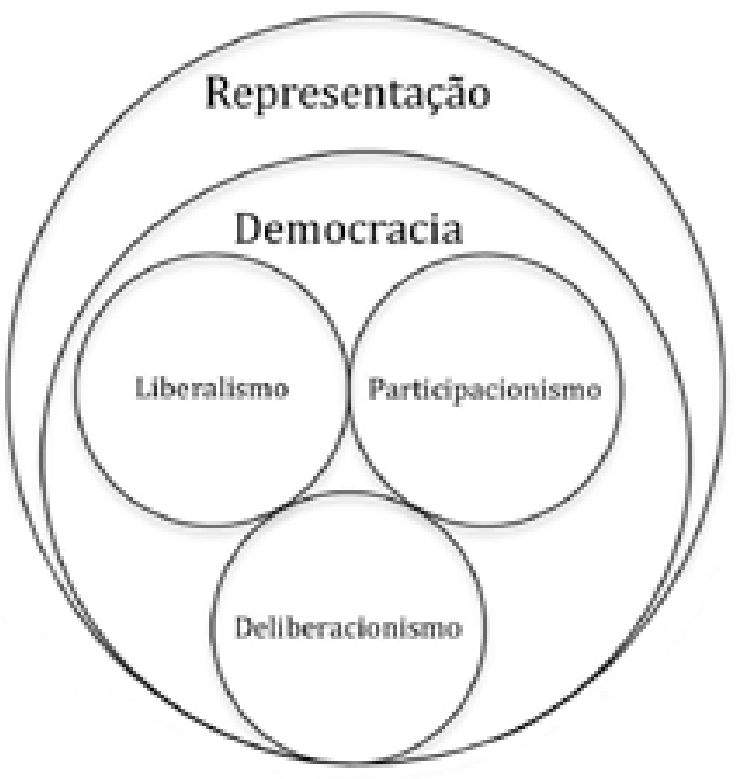


Antes de terminar esta seção, é ainda importante notar que, ao se tratar a representação como uma relação social, necessariamente se percebe que a representação se desenvolve, ao menos em sua grande parte, como uma relação social mediada, em que se estabelecem os laços originais entre representação e comunicação. Afinal, as relações da representação política, que acabam por constituir o dia a dia da política, são em geral mediadas, ou seja, intermediadas por partidos, organizações civis ou não-governamentais, movimentos sociais, empresas, organizações midiáticas e aparatos tecnológicos, de um modo que a representação não somente agrega as preferências dos representados, mas também as forma e transforma (Castiglione; Warren, 2006).

\section{COMUNICAÇÃO E REPRESENTAÇÃO}

A partir do que foi debatido anteriormente, esta seção tem por objetivo pensar a relação entre comunicação e representação. Nesse sentido, irá: 1) discutir uma teoria da comunicação para a representação; e 2) refletir sobre comunicação e representação democrática como comunicação e representação na democracia, de modo que, ao fim, seja possível deixar a sugestão de que essa relação não deve ser pensada somente por meio de uma visão transmissiva da comunicação, mas também em sua qualidade ritualística (Carey, 1989).

Segundo Carey (1989), enquanto uma visão transmissiva da comunicação tem como foco a transmissão de signos, símbolos ou mensagens no espaçotempo e os impactos desse movimento em uma certa recepção coletiva ou individual, a perspectiva ritualística está mais ligada a termos como "compartilhar", "compartilhamento", "comum", "comunidade", "comunhão". Enquanto a primeira é vista como uma série de processos, permeados por aparatos tecnológicos, de disseminação ou transmissão de mensagens, conhecimento, ideias ou informação, onde estariam presentes os "efeitos da mídia" (media effects) sobre a sociedade, a política e, em última instância, a realidade (Bryant; Oliver, 2009), a perspectiva ritualística, que não exclui a transmissiva mas acrescenta outra dimensão ao debate, é direcionada não à transmissão da mensagem no espaço-tempo e seus efeitos em uma realidade social específica e geograficamente limitada, mas às culturas e linguagens que se constituem no ambiente comunicacional e perpetuam a sociedade no tempo, à representação e reprodução de "crenças comuns" e o compartilhamento de ideias - comunicação como cultura -, algo que, de certa forma, conecta o pragmatismo americano aos estudos culturais britânicos e às perspectivas construtivistas da teoria social (Berger; Luckmann, 1967; Carey, 1989; Hall, 1997). 
Nesse contexto, é importante perceber que, do mesmo modo que as novas perspectivas da teoria da representação, a visão ritualística traz o benefício de acrescentar um certo relativismo epistemológico ao debate. Afinal, da mesma maneira que Dewey afirma que a sociedade não existe somente através da transmissão (by transmission) ou através da comunicação (by communication), mas também na transmissão e na comunicação (Dewey, 1927 citado por Carey, 1989, p. 11), sugere-se aqui que a representação não somente se materializa, entre outras coisas, da comunicação envolvida na prática, mas também está na comunicação e dela não pode ir além, como uma expressão (fala) que não pode ultrapassar sua cultura (linguagem). Assim, é possível pensar a relação entre comunicação, representação e democracia a partir do diagrama exposto na Figura 3 a seguir: democracia na representação, representação na comunicação (como cultura).

FIGURA 3: Representação na comunicação

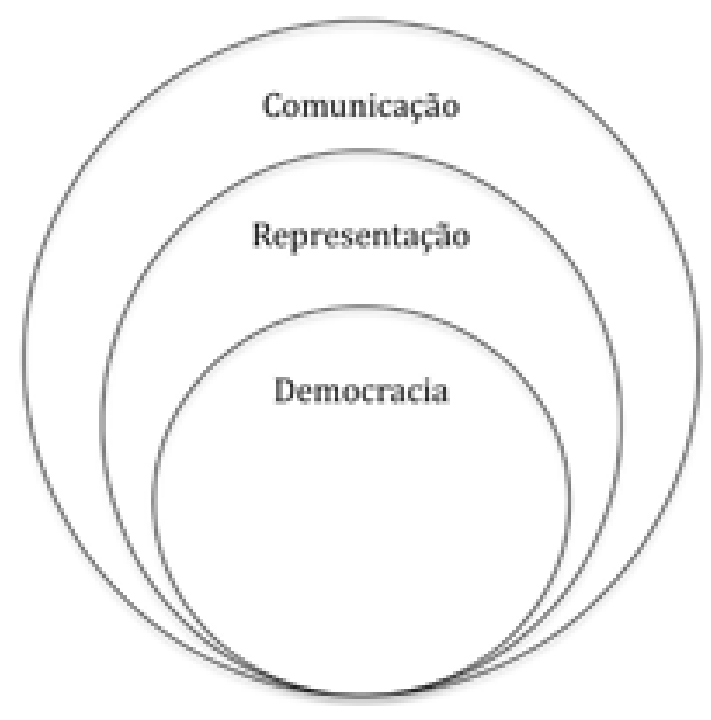

Ou mais detalhadamente na Figura 4: 
FIGURA 4 : Liberalismo, participacionismo e deliberacionismo na representação

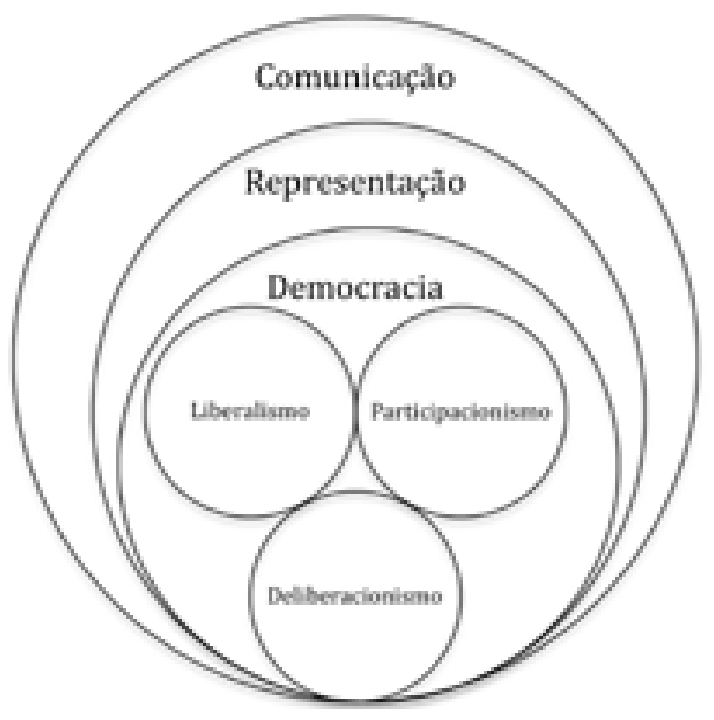

Nesse sentido, com as duas noções de comunicação em mãos, este trabalho propõe pensar comunicação e representação democrática como comunicação e democracia na representação, o que significa analisar a relação entre comunicação e representação a partir dos cruzamentos entre as noções de liberalismo na representação, participacionismo na representação e deliberacionismo na representação com as perspectivas transmissiva e ritualística da comunicação, como nas figuras 5 e 6 a seguir.

FIGURA 5: Comunicação como transmissão e democracia

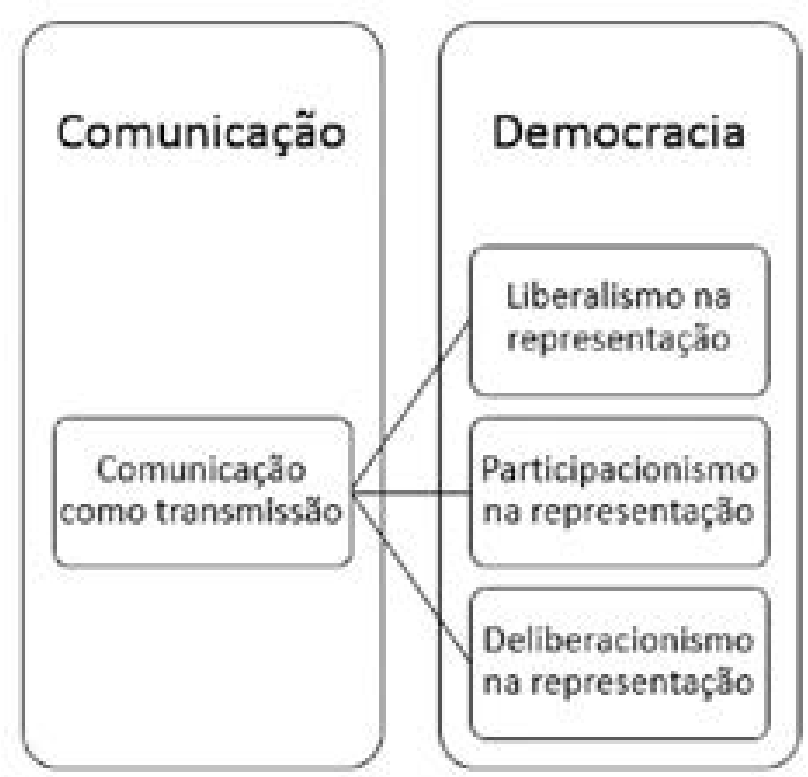


FIGURA 6: Comunicação como rito e democracia

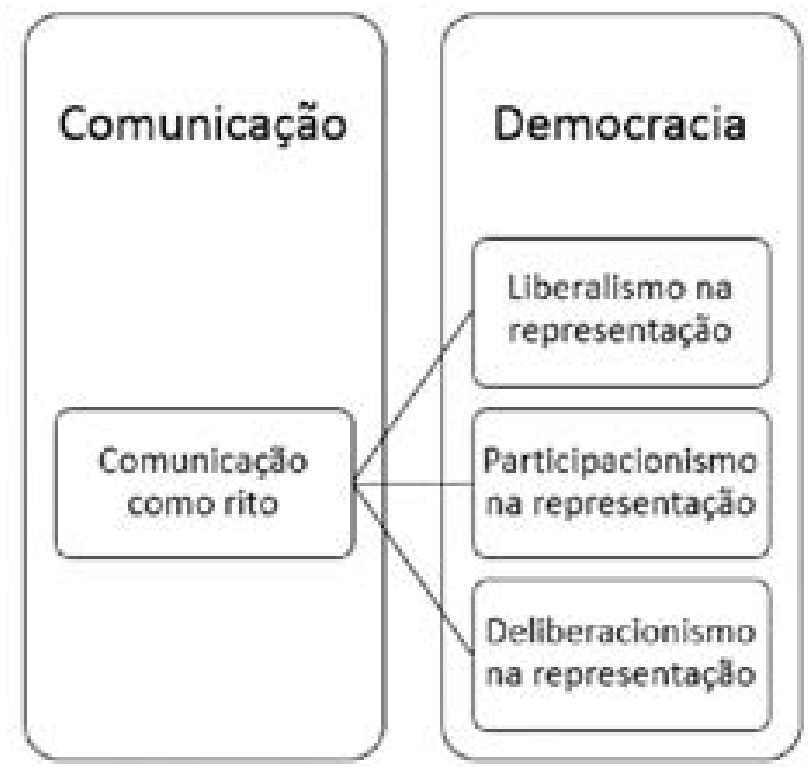

No que diz respeito à tradição liberal, por exemplo, que centraliza suas forças na autonomia privada do cidadão, nas liberdades e direitos contra a tirania e o autoritarismo estatal ou social, pode-se enfatizar, no terreno da comunicação e democracia, o direito e a liberdade de expressão, bem como a pluralidade de opiniões que forçariam o poder público a obedecer critérios mínimos de transparência, prestação de contas, responsividade e proteção do indivíduo. Isso se daria por meio da visibilidade pública mediada pelos meios de massa, contra os arbítrios privados e públicos e em prol das liberdades e da igualdade política no interior da comunidade (Gomes; Maia, 2008, p.14). Nesse contexto, o cruzamento entre a noção de liberalismo na representação e uma visão transmissiva da comunicação poderia apontar, entre outras coisas, para problemas como a concentração na posse das grandes organizações midiáticas, a dependência do cidadão em organizações de cunho comercial na provisão da informação política, a falta de transparência dos processos decisórios, a autonomização dos representantes e o populismo político midiático.

No campo do republicanismo, o cruzamento entre participação e comunicação mostraria preocupação com o favorecimento ou o impedimento à participação política gerado pelas linguagens e meios de comunicação de massa (Gomes; Maia, 2008, p. 14). Além disso, colocaria questões à cultura política e às instituições, como ambientes que favoreceriam ou prejudicariam o engajamento na formulação e resolução de problemas comuns (Maia; Gomes; Marques, 2011; Ituassu, 2011). Nesse contexto, enquanto iniciativas mais participativas, propriamente ditas, almejariam um input efetivo no processo 
decisório, a participação na representação manteria a autonomia relativa do representante, com seu papel limitado à participação discursiva que poderia reforçar as demandas por responsividade.

Já no campo do deliberacionismo, o cruzamento entre a deliberação e comunicação consideraria os fluxos de comunicação presentes nas arenas públicas, onde problemas comuns são formulados, discutidos, enunciados e examinados, ou seja, a "esfera pública política", que forma uma "opinião pública política", que refletiriam os interesses eas preferências dos representados (Gomes; Maia, 2008, p. 17). Da mesma maneira que no participacionismo, a deliberação na representação se distinguiria da proposta deliberativa propriamente dita ao não colocar ênfase na noção de "esfera intermediária" entre o debate público e a decisão política, garantindo a autonomia relativa do representante, mas no seu papel potencializador de contextos discursivos que possam reforçar as demandas por responsividade por parte dos representantes.

$\mathrm{Na}$ relação das três perspectivas da democracia com uma visão ritualística da comunicação, isto é, como um compartilhamento constituinte da comunidade no tempo, novas agendas entram em campo. Está em jogo agora não o efeito da comunicação na prática representativa, mas a constituição de uma cultura política da qual o ato representativo é dependente - representação na comunicação. Ao ver deste trabalho, uma reflexão sobre a relação entre representação e comunicação como rito deve levar em conta: 1) a pluralidade do ambiente comunicativo e a publicidade das questões envolvidas no ato representativo; 2) a participação discursiva do cidadão na constituição da cultura política na qual a representação estará inserida; e 3) a qualidade do debate público e os processos de construção social da representação.

O primeiro ponto nasce do cruzamento da perspectiva liberal na representação com uma noção ritualística de comunicação. A partir dessa interseção, ganha importância a pluralidade no ambiente comunicativo e a publicidade das questões envolvidas no sentido de se assegurar uma autoridade atomizada sobre a construção social e discursiva da cultura política que irá informar a prática representativa (representação na comunicação). Já o cruzamento entre uma perspectiva participacionista na representação com uma visão ritualística da comunicação poderia ressaltar a necessidade de se reforçar a voz do indivíduo, cidadão ou representado nos processos discursivos de construção social da cultura política. Por fim, a interseção entre o deliberacionismo na representação e uma visão ritualística da comunicação poderia chamar a atenção para uma noção de representação na discussão 
pública, ou seja, a ideia de que, parafraseando James Carey, "politics is a conversation"2.

A partir desse cruzamento, a teorização se aproximaria da qualidade existencial do debate público nos diferentes espaços discursivos e os processos de construção social da representação. Nesse contexto, tornam-se importantes as várias instâncias nas quais o discurso público toma lugar e as diferentes conversas que se dão nas esferas discursivas da sociedade, e o foco é deslocado da decisão ou produto do ato representativo para a discussão presente no seu processo de construção social - "How does political will come into being?" (Näström, 2011, p. 503).

\section{COMUNICAÇÃO, INTERNET E REPRESENTAÇÃO}

Dessa forma, a partir das duas discussões desenvolvidas anteriormente, o objetivo desta seção é sugerir uma teoria sobre as potencialidades da comunicação política digital para a representação democrática, a partir do cruzamento entre as perspectivas normativas da teoria da democracia na representação (liberalismo na representação, participacionismo na representação, deliberacionismo na representação) e as noções transmissiva e ritualística da Web, como nas figuras 7 e 8 a seguir.

FIGURA 7: A Web como transmissão e democracia

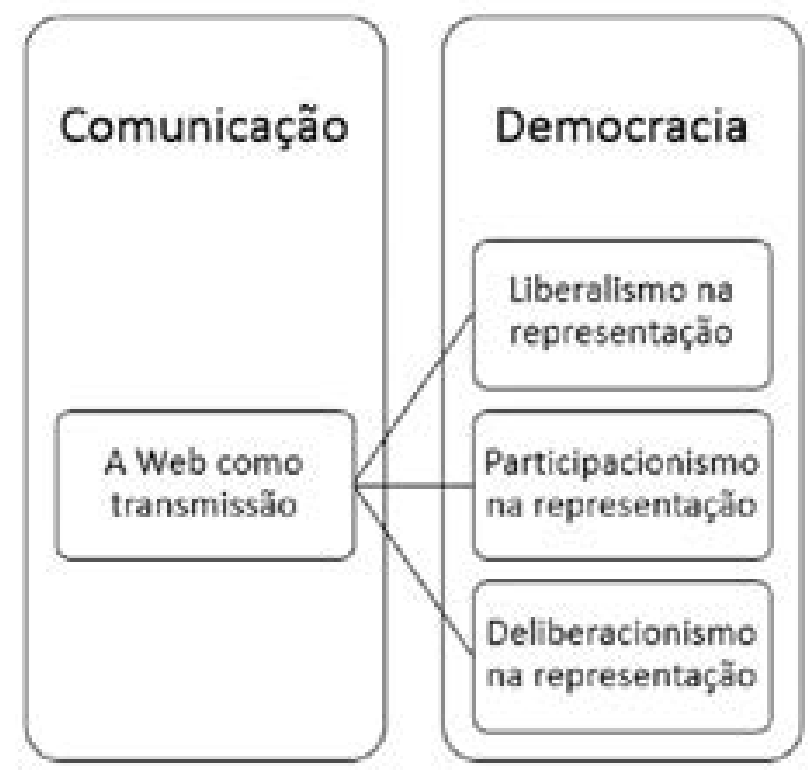

2 A frase original é "Life is a conversation" (CAREY, 1989, p. IX). 
FIGURA 8: A Web como rito e democracia

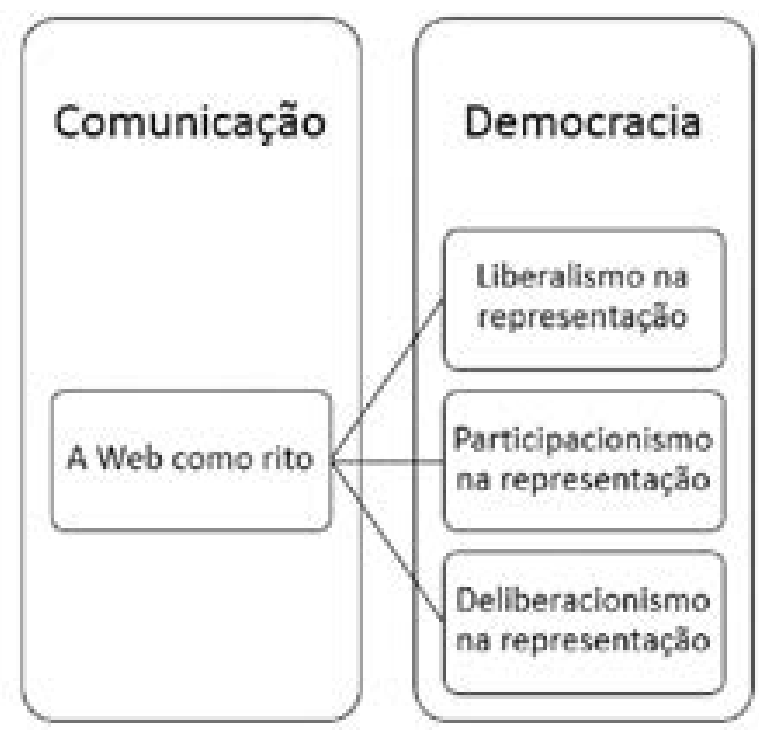

Antes disso, no entanto, é importante ressaltar que a relação entre internet e representação política já foi pensadas anteriormente. Coleman e Blumler (2010), por exemplo, ressaltam as possibilidades de inovações institucionais no mundo virtual que poderiam despertar uma cidadania mais crítica, ao mesmo tempo em que levariam o governo representativo para uma nova forma de respeito ao discurso público e à deliberação. Para os autores, o estado atual das democracias contemporâneas requer a criação de novos espaços para a prática da cidadania, e a internet, afirmam, apresenta o potencial de revitalizar os arranjos desgastados da comunicação política contemporânea, injetando novos elementos na relação entre representantes e representados. Com isso, eles sugerem a criação de comunidades cívicas (civic commons) (p. 170), algo como um novo tipo de agência criada para romper com os limites da comunicação política atual e conectar a voz do público ao dia a dia das instituições.

De modo semelhante, Karlsson (2013, p.3) chama a atenção para uma"série de tendências convergentes" que teriam atualizado o tema da "interatividade na representação política". O autor, cita, por exemplo as transformações na atitude do cidadão para com os partidos e as instituições da democracia representativa, a percepção de que as novas tecnologias de informação possibilitam uma renovação da comunicação política nas sociedades contemporâneas, o desenvolvimento de novas formas participativas de governo e as novas esferas interativas da sociedade (Coleman, 2005).

Com isso, Karlsson (2003, p. 17) concebe uma "representação como interação", capaz de proporcionar compensações estratégicas ao agente político. 
No campo da prestação de contas, por exemplo, reforçaria a legitimidade das decisões. Como meio de prospecção, facilitaria a geração de conhecimento para decisões e campanhas. Como elemento de vinculação, criaria um relacionamento mais próximo e de mais confiança na representação.

Em meio a esse debate, argumenta-se aqui que a contribuição da comunicação política digital para a representação democrática está menos no estabelecimento de vínculos mais diretos, ou interatividade entre representantes e representados, e mais no fortalecimento, além dos preceitos liberais, de práticas digitais de deliberação e participação na representação, que poderiam gerar formas mais densas de responsividade por parte dos representantes e mais oportunidades, por parte dos representados, nos processos de construção social da representação. Tal conclusão se viabilizaria não tanto a partir do cruzamento entre as noções de liberalismo, participacionismo e deliberacionismo na representação com uma perspectiva transmissiva do ambiente online, mas fundamentalmente na interseção destas mesmas noções com uma visão ritualística da Web.

Se o cruzamento entre a noção de liberalismo na representação e uma visão transmissiva da comunicação apontaria, como já foi debatido, para os problemas como a concentração na posse das organizações midiáticas, a dependência cidadã dessas organizações de lógica comercial na provisão da informação, a falta de transparência dos processos decisórios, a autonomização dos representantes e o populismo político midiático, contribuições que poderiam vir da internet estariam no campo da informação, transparência, visibilidade e publicidade dos processos políticos representativos (Gomes; Maia, 2008; Welch, 2012; Naurin; Fellow; Shuman, 2007; Marques, 2014). Como liberalismo e representação são noções praticamente interligadas - de onde significa dizer que, ao menos em última instância, tanto o participacionismo como o deliberacionismo são formas alternativas à representação -, fortalecer práticas liberais é tanto incrementar a representação quanto fortalecer a representação é incrementar o liberalismo democrático.

Na arena republicana, o cruzamento entre a participação na representação e uma visão transmissiva da comunicação no contexto digital levaria o debate em direção ao uso político das novas mídias de modo a promover a participação discursiva dos cidadãos. Com isso, a missão online republicanista na representação seria de incrementar o pluralismo da fala política, as liberdades de expressão, opinião e argumentação, as oportunidades discursivas, a visibilidade e o controle discursivo sobre o processo decisório e a sua transparência, podendo 
com isso gerar, como já se sugeriu antes, formas mais densas de responsividade no processo representativo.

Finalmente, no campo do deliberacionismo, o cruzamento entre a deliberação na representação e uma visão transmissiva da comunicação colocaria o ambiente digital como possível elemento multiplicador de esferas públicas e potencializador do debate público, com a criação e mediação de novos espaços, fluxos e esferas de comunicação, contribuindo também para a geração de responsividade (à opinião pública) no processo representativo.

Por outro caminho, isto é, o cruzamento das três perspectivas da teoria da democracia com uma noção ritualística da comunicação digital, ao menos três pontos ganham destaque: 1) a pluralidade no ambiente online e a publicidade das questões envolvidas na prática representativa; 2) a participação discursiva digital cidadã na constituição da cultura política representativa; e 3) o debate público online e os processos de construção social da representação.

O primeiro ponto é fruto do cruzamento da perspectiva liberal na representação com a noção de comunicação digital como um rito. A partir dessa interseção, ganha importância o acompanhamento sobre a pluralidade, visibilidade e publicidade de posições e das questões envolvidas no ambiente online, no sentido de se assegurar uma autoridade atomizada sobre a construção social da cultura política que informa a prática representativa. Já o cruzamento entre a perspectiva participacionista na representação com uma visão ritualística da Web poderia ressaltar a necessidade de se dar oportunidade e visibilidade à voz do cidadão ou do indivíduo representado na constituição da cultura política onde se insere a prática representativa. Por fim, a interseção entre o deliberacionismo na representação e uma visão ritualística da internet teria como foco a qualidade existencial do debate público online e os processos discursivos de construção social da representação.

Dessa forma, da inclusão da perspectiva ritualística no debateé que surge a noção de que a contribuição da comunicação política digital para a representação democrática está menos no estabelecimento de vínculos mais diretos ou interatividade entre representantes e representados e mais no fortalecimento, além dos preceitos liberais tradicionais, de práticas digitais de deliberação e participação na representação, que poderiam gerar formas mais densas de responsividade, por parte dos representantes e mais oportunidades, por parte dos representados, de participação nos processos discursivos de construção social da representação - representação na comunicação. Tal conclusão se viabilizaria não tanto a partir do cruzamento entre as noções de liberalismo, participacionismo e deliberacionismo na representação com a perspectiva 
transmissiva da comunicação no ambiente digital, mas fundamentalmente na interseção destas mesmas noções com uma visão ritualística da Web.

\section{CONCLUSÃO}

Para chegar até aqui, este trabalho percorreu pelo menos três passos. Em um primeiro momento, discutiu o lugar da representação nas teorias política e democrática. Em seguida, debateu a relação entre comunicação e representação. Ao fim, fez uma reflexão sobre o potencial da comunicação política digital para a representação democrática.

Em primeiro lugar, foi sugerida uma noção de representação política como uma relação social constituída de significados políticos socialmente compartilhados, o que acabaria por posicionar a representação na teoria política e democrática de modo que os direitos, a participação ou a deliberação cidadã possam ser pensados na representação (liberalismo na representação, participacionismo na representação, deliberacionismo na representação). Em segundo lugar, este trabalho procurou pensar a relação entre comunicação e representação pelo cruzamento entre as perspectivas normativas da teoria da democracia na representação e as visões transmissiva e ritualística da comunicação. A esperança era a de que, com esse arcabouço teórico em mãos, fosse possível debater as potencialidades da internet para a representação democrática.

Nesse sentido, foi feita uma reflexão com base no cruzamento entre o liberalismo na representação e uma visão transmissiva da Web, que chama a atenção para a qualidade da informação política, a descentralização do ambiente comunicacional e a abertura de oportunidades e lógicas de produção comunicativa online. Além disso, uma contribuição da internet poderia ser a de trazer mais transparência e publicidade ao processo representativo, disponibilizando informações sobre atividades e decisões de agentes e instituições envolvidas.

A partir da interseção entre o participacionismo na representação e o deliberacionismo na representação com uma visão transmissiva da internet, ressaltou-se o potencial de incremento da participação discursiva, do pluralismo da fala política, das liberdades de expressão, opinião e argumentação, das oportunidades de controle discursivo sobre os processos políticos representativos, do debate público e da criação e mediação digital de novos espaços, fluxos e esferas de comunicação, como uma contribuição ao desenvolvimento da prática representativa. Nesse contexto, foi sugerido 
que, enquanto iniciativas mais participativas e deliberativas per se almejam um input do cidadão ou do debate com maior efetividade nos processos decisórios, a participação e a deliberação na representação mantêm a autonomia do representante, tendo seus papeis dirigidos à promoção de formas mais densas de responsividade.

Finalmente, a partir do cruzamento das três perspectivas normativas da democracia na representação com uma visão ritualística da comunicação digital, foi sugerido que uma teoria nesse campo deve levar em consideração: 1) a pluralidade, visibilidade e publicidade da comunicação online constitutiva da realidade social representativa; 2) a participação cidadã discursiva na constituição da cultura política representativa no ambiente digital; e 3) o debate público na internet e os processos de construção social da representação.

Ao fim do caminho, a sugestão que esta análise gostaria de deixar é a de que a contribuição da comunicação política digital para a representação democrática está menos no estabelecimento de vínculos mais diretos ou interatividade entre representantes e representados e mais no fortalecimento, além dos preceitos liberais, de práticas digitais de deliberação e participação na representação, que poderiam gerar formas mais densas de responsividade, por parte dos representantes, e mais oportunidades de participação, por parte dos representados, nos processos discursivos de construção social da representação.

\section{REFERÊNCIAS}

AGGIO, C. Internet, eleições e participação: Questões-chave acerca da participação e do ativismo nos estudos em campanhas online. In: MAIA, R. C. M.; GOMES, W.; MARQUES, F. P. J. A. (orgs.). Internet e participação política no Brasil. Porto Alegre: Sulina, p.175-195, 2011.

BERGER, P. L.; LUCKMANN, T. The Social Construction of Reality: A Treatise in the Sociology of Knowledge. Nova York: Anchor Books, 1967.

BRYANT, J.; OLIVER, M. B. (eds.). Media Effects: Advances in Theory and Research. Nova York: Routledge, 2009.

CAREY, J. Communication as Culture. Nova York: Routledge, 1989.

CASTIGLIONE, D.; WARREN, M. E. Rethinking Democratic Representation: Eight Theoretical Issues. Rethinking Democratic Representation, Centre for the Studies of Democratic Institutions, University of British Columbia, 2006.

COLEMAN, S. New Mediation and Direct Representation: reconceptualizing representation in the digital age. New Media and Society, vol.7, n.2, p. 177198, 2005. 
COLEMAN, S.; BLUMLER, J. G. The Internet and Democratic Citizenship: Theory, Practice and Policy. Cambridge: Cambridge University Press, 2010.

CHADWICK, A.; HOWARD, P. N. The Routledge Handbook of Internet and Politics. Nova York: Routledge, 2009.

DAHLGREN, P. The Public Sphere and the Net: Structure, Space, and Communication. In: BENNETT, W. L.; ENTMAN, R. M. Mediated Politics. Cambridge: Cambridge University Press, p. 33-55, 2001.

GARCÊZ, R. L. de O. Lutas por reconhecimento dos surdos e conversação política no Orkut: Quando temas sensíveis definem a trajetória das discussões. In: MAIA, R. C. M.; GOMES, W.; MARQUES, F. P. J. A. (orgs.). Internet e participação política no Brasil. Porto Alegre: Sulina, p. 231-256, 2011.

GOMES, W. Participação política online: questões e hipóteses de trabalho. In MAIA, R. C. M.; GOMES, W.; MARQUES, F. P. J. A. (orgs.). Internet e participação política no Brasil. Porto Alegre: Sulina, p. 19-46, 2011.

GOMES, W.; MAIA, R. C. M. Comunicação e democracia: Problemas e perspectivas. São Paulo: Paulus, 2008.

HALE, M.; MUSSOM, J.; WEARE, C. Developing digital democracy: Evidence from Californian municipal web pages. In: LOADER, B; HAGUE, B. (orgs.). Digital Democracy: Discourse and decision making in the information age. Nova York: Routledge, 1999.

HALL, S. (ed.). zepresentation: Cultural Representations and Signifying Practices. Los Angeles: Sage, 1997.

HELD, D. Models of Democracy. Stanford: Stanford University Press, 2006.

ITUASSU, A. Participação, cidadania e ciber-república no Brasil. E-Compós, v.14, n.2, p.1-13, mai/ago. 2011.

KARLSSON, M. Representation as interactive communication. Information, Communication \& Society, DOI:10.1080/1369118X.2012.757633, 2013.

LAVALLE, A.G.; ARAUJO, C. O futuro da representação: Nota introdutória. Lua Nova, n.67, p. 9-13, 2006.

LAVALLE, A.G.;HOUTZAGER, P.;CASTELLO, G. Democracia, pluralização da representação e sociedade civil. Lua Nova, n.67, p. 49-103, 2006.

MAIA, R. C. M. Deliberation, the media and political talk. Nova York: Hampton Press, 2012.

MAIA, R. C. M. Redes cívicas e internet: Efeitos democráticos do associativismo. In: GOMES, W.; MAIA, R. C. M. Comunicação e democracia. São Paulo: Paulus, 2008. 
MAIA, R. C. M.; GOMES, W.; MARQUES, F. P. J. A. (orgs.) Internet e participação política no Brasil. Porto Alegre: Sulina, 2011.

MANSBRIDGE, J. Rethinking Representation. American Political Science Review, vol. 97, n. 4, Novembro, p. 515-528, 2003. Representation Revisited. Democracy \& Society, vol.2, n.1, p. 14-19, 2004.

MARQUES, F. P. J. A.; SAMPAIO, R. C.; AGGIO, C. (orgs.). Do clique à urna: Internet, redes sociais e eleições no Brasil. Salvador: EDUFBA, 2013.

MENDONÇA, R. F. Representation and Deliberation in Civil Society. Brazilian Political Science Review, vol.2, n.2, p. 117-137, 2008.

MIGUEL, L. F. Representação política em 3D: Elementos para uma teoria ampliada da representação política. Revista Brasileira de Ciências Sociais, vol.18, n.51, p. 123-193, fev. 2003.

MIOLA, E. Iniciativas institucionais de deliberação online: Um estudo do fórum de discussão do portal da Câmara dos Deputados. In: MAIA, R. C. M.; GOMES, W.; MARQUES, F. P. J. A. (orgs.). Internet e participação política no Brasil. Porto Alegre: Sulina, p. 147-174, 2011.

NÄSTRÖM, S. Where is the representative turn going? European Journal of Political Theory, vol.10, n.4, p. 501-510, 2011.

NAURIN, D.; FELLOW, M.; SHUMAN, R. Transparency, publicity, accountability: The missing links. Swiss Political Science Review, vol.12, n.3, p. 90-98, 2007.

PETIT, P. Varieties of public representation. In: SHAPIRO, I.; STOKES, S. C.; WOOD, E. J.; KIRSHNER, A. S. (eds.). Political Representation. Nova York: Cambridge University Press, p. 61-89, 2009.

PITKIN, H. The Concept of Representation. Berkeley: University of California Press, 1967.

PLOTKE, D. Representation is Democracy. Constellations, vol.4, n.1, p. 19-34, 1997.

RICHARD, E. Tools of governance. In: LOADER, B; HAGUE, B. (orgs.). Digital Democracy: Discourse and decision making in the information age. Nova York:Routledge, 1999.

REHFELD, A. Representation Rethought: On Trustees, Delegates, and Gyroscopes in the Study of Political Representation and Democracy. American Political Science Review, vol.103, n.2, p. 214-230, mai. 2009.

SAWARD, M. The Representative Claim. Nova York: Oxford University Press, 2010.

SHAPIRO, I.; STOKES, S. C.; WOOD, E. J.; KIRSHNER, A. S. (eds.). Political Representation. 
Nova York: Cambridge University Press, 2009.

URBINATI, N. Representative Democracy: Principles and Genealogy. Chicago: University of Chicago Press, 2008.

VIEIRA, M. B.; RUNCIMAN, D. Representation. Londres: Polity Press, 2008.

WELCH, E. W. The relationship between transparent and participative government: A study of local governments in the United States. International Review of Administrative Sciences, vol. 78, n. 1, p. 93-115, 2012.

YOUNG, I. M. Justice and the Politics of Difference. Nova Jersey: Princeton University Press, [1990]2011.

I. M. Representação política, identidade e minorias. Lua Nova, n. 67, p. 139190, 2006.

Recebido em: 08 janeiro 2015

Aceito em: 05 fevereiro 2015

Endereço do autor:

Arthur Ituassu <ituassu@puc-rio.br>

Departamento de Comunicação Social

Pontifícia Universidade Católica do Rio de Janeiro

Rua Marquês de São Vicente, 225, 6 andar, sala K606, Prédio Kennedy,

Gávea - Rio de Janeiro, RJ - Brasil - 22451-900 